\title{
Correlation of Electrocardiographic Isointegral Maps of Heart Atrial Activation with Selected Isopotential Maps
}

\author{
Katarína Kozlíková *, Michal Trnka \\ Institute of Medical Physics, Biophysics, Informatics and Telemedicine, Faculty of Medicine, Comenius University in Bratislava, Sasinkova 2, 81372 \\ Bratislava, Slovak Republic
}

\begin{abstract}
We compared a single beat isointegral P wave map with three specially selected isopotential P wave maps of each subject using Pearson correlation coefficient to find out whether it is possible to substitute an isointegral $P$ wave map with any suitable isopotential map. The best correlation between the isointegral map and the isopotential maps was at the instant of the highest maximum during the $\mathrm{P}$ wave, the worst correlation was at the instant of the lowest minimum during the P wave. The men's maps correlated significantly better than the women's maps. Our results showed that the supposed substitution is possible in healthy subjects at selected instants.
\end{abstract}

Keywords: body surface potential mapping; isointegral map; isopotential map; atrial activation; correlation coefficient; root mean square signal.

\section{Introduction}

Electrocardiographic body surface mapping is a non-invasive method that gives information about electric activity of the heart that cannot be obtained from the standard 12-lead electrocardiograms. The mostly used outcome of this method is in form of maps - two-dimensional or three-dimensional graphs displaying the electric potential distribution over the chest surface in a single instant (isopotential maps) or during longer time intervals (isointegral maps representing voltage-time integrals) [1].

Although roughly 3000 of papers are registered in the PubMed database concerning body surface potential mapping, only approximately $5 \%$ of them deal with atrial activation. This can be caused by the fact that it is sometimes difficult to register, to evaluate and mainly to interpret the $P$ waves.

According to a study of over 1450 apparently healthy Caucasian adults, the amplitude of a $P$ wave obtained from standard chest leads $V_{1}$ to $V_{6}$ varies between $-0.169 \mathrm{mV}$ and $0.169 \mathrm{mV}$ [2]. When using usual voltage calibration (1 mV/ $10 \mathrm{~mm}$ ), the "height" of waves would be less than $2 \mathrm{~mm}$. Because of such low amplitudes, it is sometimes very difficult to find the exact onset (beginning) and the exact offset (end) of a P wave as the noise may influence their setting very much. These time instants may change by more milliseconds (ms) when using different algorithms, for example, a root mean square signal for all electrocardiograms or a sequence of isopotential maps. As the P waves are relatively flat, even a small shift of the beginning and/or the end of the wave may influence the form of isointegral maps that are used for clinical purposes [3 - 5].

The aim of this study is find out whether the P wave isointegral maps correlate with selected isopotential maps to such extent that they might be substituted with 
appropriate isopotential maps evaluated in such selected time instants that are not influenced by the beginning and/or the end of the wave.

\section{Experimental Section}

Westudied body surface maps in 40 healthyyoung adults (20 women, 20 men; 18 - 19 years old). The studied subjects had no history of cardiovascular diseases and revealed abnormal findings neither in the standard 12-lead electrocardiograms, nor in the M-mode echocardiograms.

We recorded 24 unipolar electrocardiograms according to Barr in supine position (Figure 1) using the mapping system ProCardio [6; 7]. All data were filtered for $50 \mathrm{~Hz}$ and noise. Linear baseline was taken through the T-P segments in each trace. We established the onset and the offset of the P wave from the root mean square (RMS) signal

$$
R M S=\sqrt{\frac{\sum_{i=1}^{N} U_{i}}{N}}
$$

where $U_{i}$ is the voltage in the $i^{\text {th }}$ lead, $i=1,2,3 \ldots N$; $N$ is the total number of leads in the map [1].

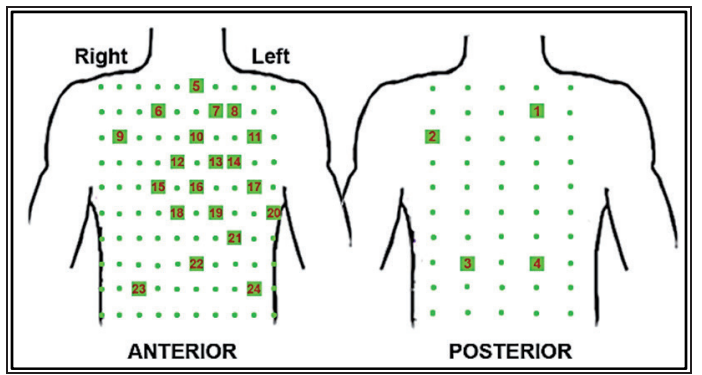

Fig. 1: Limited 24-lead system according to Barr. The positions of 24 leads (small squares) are displayed that are used to construct a map in form of a $10 \times 15$ matrix (dots) [6].

From the measured 24 leads, all maps were constructed to display the potential distributions in form of matrices consisting of 10 rows and 15 columns [6]. We always compared one single beat isointegral map with three isopotential maps of each subject using Pearson correlation coefficients $r$ [8] at the instants of the highest maximum in the sequence of isopotential maps (MAX), of the lowest minimum in the sequence of isopotential maps (MIN), and of the maximal RMS value during the total P wave, as these instants can be defined unambiguously from the onset/offset of the wave

$$
r=\frac{\sum_{i=1}^{N}\left(I_{i}-\bar{I}\right) \cdot\left(U_{i}-\bar{U}\right)}{\sqrt{\sum_{i=1}^{N}\left(I_{i}-\bar{I}\right)^{2}} \cdot \sqrt{\sum_{i=1}^{N}\left(U_{i}-\bar{U}\right)^{2}}}
$$

where $I_{i}$ is the voltage-time integral in the $i^{\text {th }}$ lead, $\bar{I}$ is the average value of the voltage-time integrals in the isointegral map, $U_{i}$ is the voltage in the $i^{\text {th }}$ lead, $\bar{U}$ is the average value of the voltages in the isopotential map, $i=1,2,3 \ldots N$; $N$ is the total number of leads in the map [1].

\section{Results and Discussion}

The mean duration \pm standard deviation (range) of the P waves was $85 \mathrm{~ms} \pm 12 \mathrm{~ms}$ ( $59 \mathrm{~ms}-105 \mathrm{~ms}$ ). Individual single beat isopotential maps revealed mainly smooth bipolar distribution of positive and negative time integrals (Figure 2 - upper part), with maxima located mainly on the left anterior chest and minima in right clavicular area or around the right shoulder, in good agreement with published data $[3 ; 4 ; 9 ; 10]$. The group average isointegral map maximum was $4.7 \mathrm{mV} \cdot \mathrm{ms} \pm 1.5 \mathrm{mV} \cdot \mathrm{ms}$ (2.4 mV.ms - $8.3 \mathrm{mV} \cdot \mathrm{ms}$ ), group average isointegral map minimum was $-3.7 \mathrm{mV} \cdot \mathrm{ms} \pm 1.7 \mathrm{mV} \cdot \mathrm{ms}$ $(-7.4 \mathrm{mV} \cdot \mathrm{ms}--1.3 \mathrm{mV} \cdot \mathrm{ms})$, group average root mean square signal (for each subject averaged throughout the total wave duration) was $2.3 \mathrm{mV} \cdot \mathrm{ms} \pm 0.8 \mathrm{mV} \cdot \mathrm{ms}$ (1.1 mV.ms $-4.0 \mathrm{mV} \cdot \mathrm{ms})$.

Although the isopotential maps distribution resembled that of the isointegral map (Figure 2), some multipolar distribution occurred in $\mathrm{P}$ wave isopotential maps with a secondary maximum often on the back, again in good agreement with published data $[1 ; 11-15]$. The group mean highest isopotential map maximum was $0.101 \mathrm{mV} \pm 0.027 \mathrm{mV}(0.057 \mathrm{mV}$ - $0.188 \mathrm{mV}$ ), the group mean lowest isopotential map minimum was $-0.090 \mathrm{mV} \pm 0.032 \mathrm{mV}(-0.166 \mathrm{mV}$ - $-0.036 \mathrm{mV})$, the group mean maximal root mean square signal in isopotential maps was $0.051 \mathrm{mV} \pm$ $0.015 \mathrm{mV}(0.027 \mathrm{mV}-0.091 \mathrm{mV})$.

The best mean correlation between IIM P and IPM P was at the MAX instant: $0.958 \pm 0.036$ (0.871 - 0.997). The mean correlation at the maximal RMS instant was $0.957 \pm 0.038(0.842-0.997)$. The worst correlation was at the MIN instant: $0.952 \pm 0.051$ (0.738 - 0.997), where the men's maps correlated statistically significantly better than the women's 


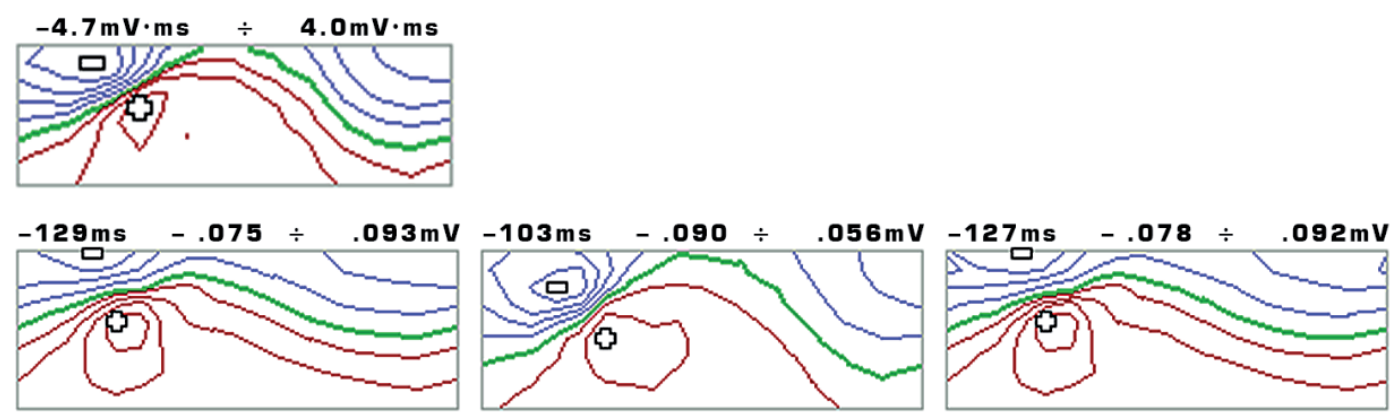

Fig. 2: An example of an isointegral P wave map (on the top) and selected isopotential maps from the same subject (a 19 years old man) at the instants $M A X$, MIN, and RMS (from left to right). Each rectangle represents the chest with the left half corresponding to the anterior chest and the right half corresponding to the back. The step between isointegral lines is $1 \mathrm{mV} \cdot \mathrm{ms}$, the step between isopotential lines is $0.02 \mathrm{mV}$; negative isolines are blue, positive isolines are red, zero isoline is thicker and green. The numbers over the maps are the time instant of the isopotential map, minimum (-) and maximum (+). Correlation coefficients between the isointegral map and the corresponding isopotential maps are: $r_{\text {MAX }}=0.871, r_{\text {MN }}=0.973$, and $r_{\text {RMS }}=0.885$.

did: $0.970 \pm 0.023(0.913-0.997)$ versus $0.934 \pm 0.064$ (0.738 - 0.987), $p<0.05$. All obtained correlation coefficients were statistically significantly different form zero value $(p<0.001)$ [8].

Our study was inspired by the fact that $P$ waves are low-amplitude deflections that might be largely influenced by noise. This occurs mainly in single-beat isopotential maps. The noise as a random influence can be suppressed either by using average cycles or by using isointegral maps, which emphasise small but long lasting events. On the other side, because of the noise, it is difficult to set the exact onset and the exact offset of the wave. Unfortunately, averaged maps may suppress some important features connected with a single beat. This seems to be a vicious circle between the isointegral and the isopotential P wave maps and we tried to cut it.

A similar study was performed in 1985 in a group of $20-24$ years old healthy young men using the 32-lead system by Lux [16]. Comparable results were obtained.

\section{Conclusions}

We found that the isointegral $P$ wave maps correlate very high with the isopotential $P$ wave maps at selected time instants. Therefore, it is possible to substitute the isointegral map with an isopotential map in healthy people at the mentioned instants, mainly at the instant of the highest $P$ wave maximum and/or at the instant of the highest root mean square value. We assume that in such cardiovascular disease which are projected into the $\mathrm{P}$ wave (for example, even left ventricular hypertrophy [17]), the correlation will be different. But this needs further studies.

\section{Acknowledgments}

This study was partially supported by the projects VEGA $1 / 0807 / 18$, Ministry of Education, Slovak Republic.

\section{References and Notes}

[1] Kozlíková K. (1990). Povrchové integralové mapy, ich charakteristiky a metódy kvantitatívnej analýzy. [Surface integral maps, their characteristics and methods of quantitative analysis]. Bratislavské lekárske Listy, vol. 91, no. 11, p. $815-823$.

[2] Appendix 1: Adult Normal Limits. (2011). In: Peter W. Macfarlane, P. W., van Oosterom, A., Pahlm, O., Kligfield, M., Janse, M., Camm, J. (Eds.). Comprehensive Electrocardiology. Springer, London p. 2058 - 2125.

[3] Sippensgroenewegen, A., Peeters, H. A., Jessurun, E. R., Linnenbank, A. C., Robles de Medina, E. O., Lesh, M. D., van Hemel, N. M. (1998). Body surface mapping during pacing at multiple sites in the human atrium. P-wave morphology of ectopic atrial activation. Circulation, vol. 97, no. 4, p. 369 -380 .

[4] Sippensgroenewegen, A., Lesh, M. D., Roithinger, F. X., Ellis, W.S., Steiner, P. R., Saxon, L. A., Lee, R. J., Scheinman, M. M. (2000). Body surface mapping of counterclockwise and clockwise typical atrial flutter: A comparative analysis with endocardial activation sequence mapping. Journal of American College of Cardiology, vol. 35, no. 5, p. 1276 1287.

[5] Ferrer-Albero, A., Godoy, E.J., Lozano, M., Martínez-Mateu, L., Atienza, F., Saiz, J., Sebastian, R. (2017). Non-invasive localization of atrial ectopic beats by using simulated 
body surface P-wave integral maps. PLoS One, vol. 12, no. 7, 23 p., [Cited on 2018-01-29]. Available at: https://doi. org/10.1371/journal.pone.0181263

[6] Barr, R.C., Spach, M. S., Herman-Giddens, G.S. (1971) Selection of the number and positions of measuring locations for electrocardiography. IEEE Transactions on Biomedical Engineering, vol. 18, no. 2, p. 125 - 138.

[7] Rosík, V., Tyšler, M., Turzová, M. (1997). PC-based device for ECG mapping. Biomediziniscshe Technik, vol. 42, no. Ergänzungsband 1, p. 159 - 162.

[8] Kozlíková, K., Martinka, J. (2009). Základy spracovania biomedicínskych meraní Il. Asklepios, Bratislava, 204 p.

[9] Ikeda, K., Kubota, I., Yasui, S. (1985). Effects of lung volume on body surface electrocardiogram. Isointegral analysis of body surface maps in patients with chronic pulmonary emphysema. Japanese Circulation Journal, vol. 49, no. 3, p. 284-291.

[10] Kozlíková, K. (2007). P-wave body surface isointegral maps in children and in young adults. Physiological Research, vol. 56, no. Suppl 1, p. S123 - S128.

[11] Taccardi, B. (1996). Body surface distribution of equipotential lines during atrial depolarization and ventricular repolarization. Circulation Research, vol. 19, no. 5, p. 865 878.

[12] Mirvis, D. M. (1980). Body surface distribution of electrical potential during atrial depolarization and repolarization. Circulation, vol. 62, no. 1, p. $167-173$.

[13] Kawano, S., Sawanobori, T., Hiraoka, M. (1983). Human body surface mapping during atrial depolarization in normal and diseased subjects. Journal of Electrocardiology, vol. 16, no. 2, p. $151-159$.

[14] Kałka, D., Jagielski, J., Banasiak, W., Sobieszczańska, M. A., Telichowski, A., Fuglewicz, A., Pieróg, M., Ponikowski, P., Jagielski, D., Kałka-Gebala, R., Gajkowski, E. (1996). Zastosowanie powierzchniowego mappingu potencjałów serca do rejestracji zjawisk elektrycznych w przedsionkach. [Use of body surface heart potential mapping for registration of electrical phenomena in the atrium]. Polskie Archiwum Medycyny Wewnetrznej. Vol. 96, no. 3, p. 234 241.

[15] Kozlíková, K., Trnka, M. (2014). The isopotential maps of atrial activation in young adult controls. Experimental \& Clinical Cardiology, vol. 20, no. 7, p. 1998 - 2004.

[16] Kozlíková, K., Hulín, I., Popperová, E., Ruščáková, L., Vavrová, V., Slavkovský, P. (1985). Isopotential and isointegral maps of atrial activation. In: Abstract Book, 12th International Congress on Electrocardiology, Minsk, p. 112.

[17] Kornreich, F., Montague, T. J., Rautaharju, P. M., Kavadias, M., Horacek, M.B., Taccardi, B. (1989). Diagnostic body surface potential map patterns in left ventricular hypertrophy during PQRST. American Journal of Cardiology, vol. 63, no. 9, p. $610-617$.

\section{Biographical notes}

Doc. RNDr. Katarína Kozlíková, CSc., was born in Bratislava, Slovakia, in 1958. She received her MS (RNDr.) degree in Nuclear Physics from the Comenius University in Bratislava in 1982, her PhD degree (CSC.) in Bionics from the Institute of Measurement Science of Slovak Academy of Sciences in Bratislava. Since 1997, she is an associate professor of Physics (received from the Comenius University in Bratislava in 1997) at the Institute of Medical Physics, Biophysics, Informatics and Telemedicine, Faculty of Medicine, Comenius University in Bratislava, being the head of this Institute in the years 1997 - 2002. Her research interests are in electrocardiography, mainly body surface potential mapping, and medical statistics. She is author of 6 university textbooks, author and co-author of over 160 full text scientific papers. Since 2012, she is the Deputy Chair of the Slovak Society of Medical Physics and Biophysics of the Slovak Medical Association.

PhDr. Michal Trnka, PhD., was born in Bratislava, Slovakia, in 1977. He received his MS degree in Biomedical Physics from the Comenius University in Bratislava in 2000, his PhD degree in Hygiene from the Comenius University in Bratislava in 2010. He is since 2000 a lecturer at the Institute of Medical Physics, Biophysics, Informatics and Telemedicine, Faculty of Medicine, Comenius University in Bratislava. His research interests are in electrocardiography, mainly body surface potential mapping. He is co-author of 6 monographies and 9 university textbooks and scripts, author and co-author of more than 20 full text scientific papers, editor and co-editor of 14 conference proceedings. 